\title{
Choline supplementation in children with Fetal Alcohol Spectrum Disorders (FASD) has high feasibility and tolerability
}

\author{
Jeffrey R. Wozniak ${ }^{1}$, Anita J. Fuglestad ${ }^{1}$, Judith K. Eckerle ${ }^{1}$, Maria G. Kroupina ${ }^{1}$, Neely C. \\ Miller $^{1}$, Christopher J. Boys ${ }^{1}$, Ann M. Brearley ${ }^{1}$, Birgit A. Fink ${ }^{1}$, Heather L. Hoecker ${ }^{2}$, \\ Steven H. Zeisel ${ }^{3}$, and Michael K. Georgieff ${ }^{1}$ \\ 1 University of Minnesota Twin Cities \\ ${ }^{2}$ Emory University \\ ${ }^{3}$ University of North Carolina at Chapel Hill Nutrition Research Institute
}

\begin{abstract}
There are no biological treatments for fetal alcohol spectrum disorders (FASD), lifelong conditions associated with physical anomalies, brain damage, and neurocognitive abnormalities. In pre-clinical studies, choline partially ameliorates memory and learning deficits from prenatal alcohol exposure. This Phase I pilot study evaluated the feasibility, tolerability, and potential adverse effects of choline supplementation in children with FASD. We hypothesized that choline would be well-tolerated with minimal adverse events. The study design was a double-blind, randomized, placebo-controlled trial. Participants included 20 children, ages $2.5-4.9 y$, with prenatal alcohol exposure and FASD diagnoses. Participants were randomly assigned to $500 \mathrm{mg}$. choline or placebo daily for nine months (10 active; 10 placebo). Primary outcome measures included feasibility, tolerability, adverse effects, and serum choline levels. Seventeen participants completed the study. Compliance was $82-87 \%$ as evidenced by parent-completed logsheets and dose counts. Periodic 24-hour dietary recalls showed no evidence of dietary confounding. Adverse events were minimal and were equivalent in the active and placebo arms with the exception of fishy body odor, which occurred only in the active group. There were no serious adverse events to research participants. This Phase I pilot study demonstrates that choline supplementation at 500 $\mathrm{mg}$ per day for nine months in children ages $2-5$ is feasible and has high tolerability. Further examination of the efficacy of choline supplementation in FASD is currently underway.
\end{abstract}

\section{Keywords}

Fetal alcohol (FAS, FASD); Treatment; Choline; Clinical trial; Children

\section{(C) 2013 Elsevier Inc. All rights reserved}

Address Correspondence: Jeffrey R. Wozniak, Ph.D., Department of Psychiatry, University of Minnesota, F256/2B West, 2450 Riverside Ave., Minneapolis, MN 55454; jwozniak@umn.edu; Phone: 612-273-9741; Fax: 612-273-9779.

Publisher's Disclaimer: This is a PDF file of an unedited manuscript that has been accepted for publication. As a service to our customers we are providing this early version of the manuscript. The manuscript will undergo copyediting, typesetting, and review of the resulting proof before it is published in its final citable form. Please note that during the production process errors may be discovered which could affect the content, and all legal disclaimers that apply to the journal pertain.

The authors have no conflict of interest to disclose. 


\section{Introduction}

With an incidence of $0.9 \%$, fetal alcohol spectrum disorders (FASD) represent a serious public health problem [1]. Fetal alcohol syndrome (FAS) is the largest single known cause of mental retardation [2]. Children with FASD exhibit an array of cognitive deficits including visual-spatial learning deficits $[3,4]$ and verbal and non-verbal memory deficits $[5,6]$. In children, a breakdown is suspected in the hippocampus-mediated encoding process $[7,8]$. Children with FASD have small hippocampi on MRI and show correlations between hippocampal size and memory impairment [8]. Currently, there are no available biological treatments for the neurocognitive deficits in FASD.

Pre-clinical studies show that choline supplementation prenatally and even postnatally, as late as days 21-30 in the rodent (equivalent to human early childhood), attenuates memory and behavioral deficits associated with prenatal alcohol exposure $[9,10]$. Postnatal choline also improves cognitive functions such as visual-spatial learning, spatial reversal learning, and fear conditioning [11].

Choline is an essential nutrient with established guidelines for adequate intake (AI) [12]. It exists in free and esterified forms. As precursors to acetylcholine and phospholipids, choline and its metabolites are critical for cell membrane formation, trans-membrane signaling, cholinergic neurotransmission, and methyl-group and lipid metabolism [12]. As with folate, deficiencies in choline lead to disruptions in neural tube closure [13, 14]. Perinatal choline levels directly influence brain development, having a permanent impact on cognition [15].

No human trials of choline in FASD have been reported. This Phase I study sought to evaluate the feasibility, tolerability, and potential adverse effects of postnatal choline supplementation in young children in a double-blind, randomized, placebo-controlled trial. It was a two-year pilot study with planned unblinding after $20^{\text {th }}$ participant. This Phase 1 study sought to evaluate tolerability in a limited number of participants, minimizing the number of participants exposed to the untested treatment. The full trial, in progress, is powered to evaluate efficacy based on cognitive outcomes in 60 participants.

One goal was to test the feasibility of parental administration of choline to preschool children with FASD. Preschool children are picky eaters [16] and more likely to refuse an oral supplement. Children with FASD often have unhealthy eating patterns; some have autistic-like taste / texture sensitivities; and many have behavioral problems that can make daily supplementation challenging. Tolerability of daily choline supplement also needed to be established. We hypothesized that a child-friendly formulation of choline (good-tasting and easily ingested) would maximize tolerability, and that minimal adverse events would occur. There were three objectives. First, we examined compliance to the protocol by monitoring participants' daily supplement consumption and by assessing for change in participants' dietary intake. Second, we examined tolerability of choline by evaluating potential adverse events. Third, we measured serum levels of choline and its metabolites to confirm that the preparation we manufactured resulted in greater bioavailable choline compared to placebo.

\section{Methods and Materials}

\subsection{Participants}

Twenty-five children with FASD (ages 2.5 - 4.9 years) were recruited from the University of Minnesota's FASD Clinic and International Adoption Clinic, of which 20 received the allocated intervention (Table 1). Fifteen participants lived with adoptive families (2 international adoptions; 13 domestic), and five participants lived with relatives. No 
participants lived with biological parents. The study took place between 2009 and 2011. As part of clinical evaluations, children were seen by a pediatric psychologist and a developmental pediatrician with formal training and more than fourteen years experience diagnosing FASD. Height and weight, measures of facial dysmorphology, neurocognitive data, and alcohol exposure data were collected in clinic [17].

We used modified Institute of Medicine (IOM) criteria [18]. If multiple growth, facial, or cognitive / behavioral measurement were available, the maximum level of abnormality was recorded. For FAS, the criteria require dysmorphic facial features, growth deficiency, and deficient brain growth. For partial FAS, a dysmorphic face and either of the following are required: growth deficiency or central nervous system (CNS) impairment (deficient brain growth or behavioral and cognitive impairment). For alcohol-related neurodevelopmental disorder (ARND), confirmed alcohol exposure is required with CNS impairment (deficient brain growth and/or cognitive or behavioral impairment). Of the 20 participants, 6 (30\%) met criteria for FAS; 5 (25\%) for partial FAS; and 9 (45\%) for ARND.

Growth deficiency was height or weight $\unlhd 10 \%$ ile [19]; Deficient brain growth included structural abnormalities and/or occipital-frontal circumference (OFC) $\leq 0 \%$ ile [20]; A dysmorphic face has two of the following: short palpebral fissures ( $\leq 10 \%$ ile) [21], thin upper lip (4 or 5 rating) [17], and smooth philtrum (4 or 5 rating) [17]. Because the criteria do not explicitly quantify cognitive and behavioral deficits, we applied Centers for Disease Control and Prevention (CDC) criteria of either global cognitive functioning $>2$ standard deviations (SD) below average or deficits of $>1$ SD in three or more domains (e.g., intellectual, language, motor, visual-perceptual, adaptive functioning, behavioral) [22]. Of 20 participants, 7 (35\%) met CNS criteria on the basis of deficient brain growth, $2(10 \%)$ had global cognitive impairment, and $19(95 \%)$ had deficits of $>1$ SD in three or more domains.

Of 20 participants, 17 had confirmed prenatal alcohol exposure, including self-report or social service records indicating heavy maternal use during pregnancy (3 or 4 rating) [17]. Minimal use did not meet this criterion. Three participants had suspected but unconfirmed alcohol exposure, but met criteria for FAS $(n=1)$ or partial FAS $(n=2)$. In 14 cases, prenatal drug use was suspected, but alcohol was the predominant substance of abuse.

Exclusion criteria included developmental disorder, neurological condition, or other medical condition affecting the brain. The presence of psychiatric co-morbidity, such as Attention Deficit Hyperactivity Disorder, was not exclusionary as co-morbidity is high in FASD [23]. All but one participant, a twin born at 36 weeks weighing 1360 grams, had a birthweight $>1500$ grams.

Procedures were approved by a University IRB, and all participants underwent a comprehensive informed consent procedure including understanding randomization to choline or placebo. Families were not compensated. A Data Safety Monitoring Board with two pediatricians and a biostatistician monitored the study. The study was registered with ClinicalTrials.Gov prior to initiation (NCT01149538).

\subsection{Allocated Intervention}

Participants were randomized to $500 \mathrm{mg}$ choline (1.25 grams choline bitartrate) or placebo daily for nine months. The allocated intervention was supplied in coded light-blocking foil packets containing a powdered, fruit-flavored drink mix that was developed for the study. Parents were instructed to administer one dose per day by mixing it with four ounces of water. The study was conducted under a Food and Drug Administration (FDA) Investigational New Drug (IND) exemption. 


\subsection{Quality Control}

Packet dosages and stability were evaluated with High Performance Liquid Chromatography by an outside laboratory. Dosage was within $0.13 \%$ of target on average and stable (within $5.2 \%$ of target dosage over the study duration).

\subsection{Outcomes}

In-person assessments were at baseline and months 1, 6, and 9. Phone visits occurred at 2 weeks and at months $2,3,4,5,7$, and 8 . Primary outcome measures included feasibility and compliance, tolerability, adverse events, and serum choline levels.

Feasibility and Compliance-Parents recorded drink proportions that were consumed each day on a calendar, providing a reason if less than $100 \%$. Full and empty packets were counted at study visits.

To evaluate potential confounding from dietary changes, the Automated Self-Administered 24-hour Recall system [24]was administered at baseline and months 6 and 9. Parents were instructed to not change the use of dietary supplements during the study. Concomitant supplement use was recorded at all study visits.

Tolerability and Adverse Events-At each in-person visit, a physician completed a physical examination and assessed for adverse events. Adverse events were also monitored during phone visits. Problems with administration were monitored monthly.

Serum Choline Levels-Parents gave the drink 3 hours before the blood draw.

Anesthetic cream was used and blood was collected by venipuncture at baseline and months 1,6 , and 9. Plasma was aliquoted and stored at $-80^{\circ} \mathrm{C}$ and shipped on dry ice to the University of North Carolina for assay of choline and its metabolites. Extraction used Bligh and Dyer's method [25]. Aqueous and organic compounds were separated, analyzed, and quantified with liquid chromatography/electrospray ionization-isotope-dilution mass spectrometry after adding internal standards labeled with stable isotopes to correct for recovery [26]. Free choline, esterified choline (phosphatidylcholine and sphingomyelin), and betaine were measured.

\subsection{Randomization and Blinding}

Participants were randomized to choline or placebo arms in a 1:1 allocation ratio using a block randomization procedure with variable block sizes. Randomization was handled independently, and the research team and participants were blinded to group assignment. Preparation, coding, tracking, and distribution of packets were handled by an Investigational Drug Service unit.

\subsection{Statistical Analyses}

This Phase I study sought to establish compliance and feasibility. Group comparisons utilized independent samples $t$-tests for normally-distributed continuous variables. Due to the non-normal, leptokurtic, distribution of many compliance variables, medians and interquartile ranges (IQR) are reported. Between-group comparisons of these compliance variables were conducted using Mann-Whitney U tests. Between-group comparisons of categorical variables were conducted using Fisher's Exact Test due to small cell sizes. The Freeman-Halton extension of Fisher's Exact Test was used for contingency tables larger than $2 \times 2$. 


\section{Results}

\subsection{Feasibility and Compliance}

Twenty-five participants were randomized (Figure 1). Five participants did not receive the allocated intervention; four (choline $=3$, placebo $=1$ ) were randomized at screening, but did not come to the baseline visit. One participant (placebo group) was diagnosed with an exclusionary condition prior to baseline. Ten participants in each group received the intervention.

Of 20 participants, 17 (85\%) completed the study. Three discontinued early; one (placebo group) discontinued after six months for reasons unrelated to the study; one (placebo group) was lost to follow-up after five months; and one (choline group) took only one dose and refused it thereafter.

Compliance was measured with parent-completed calendars and packet counts. Calendars were returned by $95 \%(n=19)$ of participants. The median percentage of logsheets completed by parents was $97 \%(\mathrm{IQR}=64-100 \%)$ of days in the study. Calendar completion did not differ between groups (choline: Median=97\%, IQR=71-100\%; placebo: Median=76\%, $\mathrm{IQR}=38-100 \%, p=0.604)$. Although this difference was non-significant, the lower median for placebo was due to two participants with poor completion ( $<25 \%)$. Participants received at least a partial dose on $87 \%$ (IQR=68-95\%) of days in the study. Dose received, based on calendars, did not differ by group (Table 2 ).

Empty packets were returned by $95 \%(n=19)$ of participants. The median percentage of empty packets returned was $82 \%$ (IQR=59-88\%) of the packets they received. Dose received, based on packet counts, did not differ by group (Table 2).

The 24-hour dietary recall data revealed no group difference in choline intake from diet at any point (Table 2). No concomitant choline supplementation was reported by any participant.

\subsection{Tolerability and Adverse Events}

Table 3 contains baseline physical symptoms and adverse events (new symptoms). Although $70 \%$ of participants reported at least one problem administering the drink, there was no group difference. Fifty-five percent reported taste problems on at least one occasion, and $75 \%$ reported non-standard administration at least once (less than full dose, dose-splitting, or using something other than water).

There was no group difference in baseline symptoms (prior to allocation). Those randomized to choline had a trend-level higher baseline rate of general health concerns (e.g., weight problems, pain, hyperactivity) despite randomization. This continued throughout the study, with a trend-level higher rate of general concerns for the choline group. There was no group difference the in the change in general concerns between baseline and follow-up, $p=0.243$.

Fishy body odor occurred (at least once) only in the choline group (choline: 56\%; placebo: $0 \% ; p=0.011$ ). It was not present at baseline in either group. It was not correlated with either the child's age or weight.

One unanticipated event was reported. A parent reported increased hyperactivity and elevated mood. These behaviors were evident prior to baseline, but reportedly increased. This resolved and the participant (placebo group) completed the study. 


\subsection{Serum Choline}

Groups did not differ in choline or betaine concentration at baseline. Choline supplementation increased choline and betaine concentrations (Table 4) at all three timepoints for the choline group relative to placebo. There were no changes in phosphatidylcholine or sphingomyelin concentrations. Although the choline group had higher sphingomyelin at baseline and one month follow-up, there were no group differences in sphingomyelin at 6 or 9 months.

\section{Discussion}

We report on Phase I of an ongoing double-blind, randomized, placebo-controlled trial of $500 \mathrm{mg}$ choline supplementation in 2.5 to 4.9 year old children with FASD for 9 months. The study demonstrates acceptable feasibility, tolerability, and minimal adverse effects. Eighty-five percent completed the trial. Protocol compliance was $82-87 \%$, similar to trials of daily nutritional supplementation in children of similar ages [27-29]. There were no serious adverse events. Adverse events were minimal and equivalent in the choline and placebo arms except for fishy body odor, which occurred only in the choline group. The odor results from trimethylamine accumulating in sweat and urine. Trimethylamine is formed when choline transporters in the small intestine are overloaded and choline reaches bacteria in the gut [30]. Trimethylamine is converted to trimethylamine oxide in the liver. Recently, in rodent models, plasma concentrations of trimethylamine oxide have been associated with atherosclerosis [31]. Splitting a choline dose reduces trimethylamine formation, allowing for straightforward management of this side-effect. Future studies should be designed to mitigate potential "unblinding" that may occur because of odor. Phase I demonstrates that daily oral choline supplementation at levels significant enough to increase serum choline and betaine is feasible and tolerable in young children with FASD. A larger trial examining efficacy is warranted and is currently underway.

The appropriate choline dose for treatment of children with FASD remains to be established. The AI for choline, which is based on age, not weight, is $200 \mathrm{mg}$ for children ages 1 to 3 years and $250 \mathrm{mg}$ for 4 to 8 years [12]. A $500 \mathrm{mg}$ dose was used to bring all participants to sufficiency and to provide additional supplementation while remaining tolerable. Typical dietary choline intake levels were not previously known for children with FASD, but we found that the majority in our studies are not meeting AI for choline [32]. A dose of $500 \mathrm{mg}$ is high, but well within the range that could be achieved through normal dietary intake (ex. two eggs) and well under the upper tolerable intake level (UL) for children of $1000 \mathrm{mg}$ per day [12].

Critical windows for choline supplementation also need to be established, but may be within the first $4-5$ years. Pre-clinical studies highlight that choline is necessary when progenitor cells are proliferating $[33,34]$. Both "early" (postnatal days 11-20) and "late" supplementation (postnatal days 21-30) significantly attenuate the cognitive deficits induced by prenatal alcohol exposure, with a slight advantage for earlier supplementation [35]. In humans, the hippocampus develops rapidly during the first two years, followed by slow, steady growth until adolescence [36]. Hippocampal differentiation and synaptogenesis occur into the fifth year. Equivalent maturation in rats occurs by postnatal day 21, within the timeframe of choline's efficacy. Similarly, in humans, hippocampus-dependent memory matures into the fourth and fifth years. The equivalent memory maturation in the rat occurs on postnatal days 15 and 16, again within the timeframe of choline's efficacy.

The mechanisms of choline's effects in FASD are not yet known, but several possibilities exist. Choline contributes to dendritic arborization in CA1, to larger cells, and to functional changes [37-40]. Supplementation also affects choline acetyltransferase levels in rat 
hippocampus resulting in improved memory [41, 42]. Neuronal production of acetylcholine is directly related to availability of choline - its precursor [43]. Choline also impacts apoptosis $[44,45]$. Lastly, choline is required for the production of phospholipids (phosphatidylcholine, sphingomyelin, and plasmalogens) that are necessary for axonal growth and myelination [15].

One limitation of the study was the reliance on parent-report for several compliance measures. Parents were informed that the study was a trial of choline supplementation to improve neurocognitive outcomes, and they could have attempted to increase their child's choline intake via supplements. Parents were explicitly asked to avoid changing the child's supplements and we monitored supplement-use throughout the study to ensure compliance. There was no evidence that this occurred and there is no reason that it would occur preferentially in either group since the study was double-blinded. The data also suggest that parents did not alter children's diets to increase choline intake.

In conclusion, choline is critical to neurodevelopment [39] and has potential as a treatment for neurodevelopmental conditions. This study confirmed our hypotheses and demonstrated that 9-month choline supplementation at $500 \mathrm{mg}$ per day is feasible and tolerable in young children with FASD. The next phase of this research, already underway, will establish whether the cognitive benefits seen in pre-clinical work will translate to human children.

\section{Acknowledgments}

This work was supported by the National Institutes of Health (5R21AA019580 \& R33AA019580) and in part by National Institutes of Health (NIH) grant P30DK056350 to the UNC-CH Nutrition Obesity Research Center.

\section{Abbreviations}

FASD Fetal alcohol spectrum disorders

FAS Fetal alcohol syndrome

AI Adequate Intake

IOM Institute of Medicine

CNS central nervous system

ARND alcohol-related neurodevelopmental disorder

OFC occipital-frontal circumference

\section{REFERENCES}

[1]. Sampson PD, Streissguth AP, Bookstein FL, Little RE, Clarren SK, Dehaene P, et al. Incidence of fetal alcohol syndrome and prevalence of alcohol-related neurodevelopmental disorder. Teratology. 1997; 56:317-26. [PubMed: 9451756]

[2]. Abel EL. An update on incidence of FAS: FAS is not an equal opportunity birth defect. Neurotoxicol Teratol. 1995; 17:437-43. [PubMed: 7565490]

[3]. Streissguth AP, Sampson PD, Olson HC, Bookstein FL, Barr HM, Scott M, et al. Maternal drinking during pregnancy: attention and short-term memory in 14-year-old offspring--a longitudinal prospective study. Alcohol Clin Exp Res. 1994; 18:202-18. [PubMed: 8198221]

[4]. Uecker A, Nadel L. Spatial but not object memory impairments in children with fetal alcohol syndrome. Am J Ment Retard. 1998; 103:12-8. [PubMed: 9678226]

[5]. Mattson SN, Riley EP, Delis DC, Stern C, Jones KL. Verbal learning and memory in children with fetal alcohol syndrome. Alcohol Clin Exp Res. 1996; 20:810-6. [PubMed: 8865953] 
[6]. Olson HC, Feldman JJ, Streissguth AP, Sampson PD, Bookstein FL. Neuropsychological deficits in adolescents with fetal alcohol syndrome: clinical findings. Alcohol Clin Exp Res. 1998; 22:1998-2012. [PubMed: 9884144]

[7]. Pei JR, Rinaldi CM, Rasmussen C, Massey V, Massey D. Memory patterns of acquisition and retention of verbal and nonverbal information in children with fetal alcohol spectrum disorders. Can J Clin Pharmacol. 2008; 15:e44-56. [PubMed: 18192705]

[8]. Willoughby KA, Sheard ED, Nash K, Rovet J. Effects of prenatal alcohol exposure on hippocampal volume, verbal learning, and verbal and spatial recall in late childhood. J Int Neuropsychol Soc. 2008; 14:1022-33. [PubMed: 18954482]

[9]. Thomas JD, Biane JS, O'Bryan KA, O'Neill TM, Dominguez HD. Choline supplementation following third-trimester-equivalent alcohol exposure attenuates behavioral alterations in rats. Behav Neurosci. 2007; 121:120-30. [PubMed: 17324056]

[10]. Thomas JD, La Fiette MH, Quinn VR, Riley EP. Neonatal choline supplementation ameliorates the effects of prenatal alcohol exposure on a discrimination learning task in rats. Neurotoxicol Teratol. 2000; 22:703-11. [PubMed: 11106863]

[11]. Wagner AF, Hunt PS. Impaired trace fear conditioning following neonatal ethanol: reversal by choline. Behav Neurosci. 2006; 120:482-7. [PubMed: 16719711]

[12]. Food and Nutrition Board. Institute of Medicine. Dietary reference intakes for thiamin, riboflavin, niacin, vitamin B6, folate, vitamin B12, panthotenic acid, biotin, and choline. National Academy Press; Washington D.C.: 1998.

[13]. Shaw GM, Carmichael SL, Yang W, Selvin S, Schaffer DM. Periconceptional dietary intake of choline and betaine and neural tube defects in offspring. Am J Epidemiol. 2004; 160:102-9. [PubMed: 15234930]

[14]. Zeisel SH. Is maternal diet supplementation beneficial? Optimal development of infant depends on mother's diet. Am J Clin Nutr. 2009; 89:685S-7S. [PubMed: 19116319]

[15]. Zeisel SH, Niculescu MD. Perinatal choline influences brain structure and function. Nutr Rev. 2006; 64:197-203. [PubMed: 16673755]

[16]. Dovey TM, Staples PA, Gibson EL, Halford JCG. Food neophobia and 'picky/fussy' eating in children: A review. Appetite. 2008; 50:181-93. [PubMed: 17997196]

[17]. Astley, SJ. Diagnostic guide for fetal alcohol spectrum disorders: the 4-digit diagnostic code. 3rd ed.. University of Washington; Seattle, WA: 2004.

[18]. Hoyme HE, May PA, Kalberg WO, Kodituwakku P, Gossage JP, Trujillo PM, et al. A practical clinical approach to diagnosis of fetal alcohol spectrum disorders: clarification of the 1996 institute of medicine criteria. Pediatrics. 2005; 115:39-47. [PubMed: 15629980]

[19]. Kuczmarski RJ, Ogden CL, Grummer-Strawn LM, Flegal KM, Guo SS, Wei R, et al. CDC growth charts: United States. Adv Data. 2000:1-27. [PubMed: 11183293]

[20]. WHO Multicentre Growth Reference Study Group. WHO Child Growth Standards: Length/ height-for-age, weight-for-age, weight-for-length, weight-for-height and body mass index-forage: Methods and development. 2006.

[21]. Hall, J.; Froster-Iskenius, U.; Allanson, J. Handbook of Normal Physical Measurements. Oxford University Press: 1989.

[22]. Centers for Disease Control and Prevention. Guidelines for identifying and referring persons with Fetal Alcohol Syndrome. Morbidity and Mortality Weekly Report. 2005; 54:1-15. [PubMed: 15647722]

[23]. O'Connor MJ, Shah B, Whaley S, Cronin P, Gunderson B, Graham J. Psychiatric illness in a clinical sample of children with prenatal alcohol exposure. American Journal of Drug and Alcohol Abuse. 2002; 28:743-54. [PubMed: 12492268]

[24]. National Cancer Institute. Automated Self-Administered 24-Hour Recall (ASA24)-Beta. National Cancer Institute; Bethesda, MD: 2009.

[25]. Bligh EG, Dyer WJ. A rapid method of total lipid extraction and purification. Can J Biochem Physiol. 1959; 37:911-7. [PubMed: 13671378]

[26]. Koc H, Mar MH, Ranasinghe A, Swenberg JA, Zeisel SH. Quantitation of choline and its metabolites in tissues and foods by liquid chromatography/electrospray ionization-isotope dilution mass spectrometry. Anal Chem. 2002; 74:4734-40. [PubMed: 12349977] 
[27]. Giovannini M, Agostoni C, Riva E, Salvini F, Ruscitto A, Zuccotti GV, et al. A Randomized Prospective Double Blind Controlled Trial on Effects of Long-Term Consumption of Fermented Milk Containing Lactobacillus casei in Pre-School Children With Allergic Asthma and/or Rhinitis. Pediatr Res. 2007; 62:215-20. [PubMed: 17597643]

[28]. Abrams SA, Hawthorne KM, Chen Z. Supplementation with 1000 IU vitamin D/d leads to parathyroid hormone suppression, but not increased fractional calcium absorption, in 4-8-y-old children: a double-blind randomized controlled trial. The American Journal of Clinical Nutrition. 2013; 97:217-23. [PubMed: 23151536]

[29]. Markowitz ME, Sinnett M, Rosen JF. A Randomized Trial of Calcium Supplementation for Childhood Lead Poisoning. Pediatrics. 2004; 113:e34-e9. [PubMed: 14702492]

[30]. Zeisel SH, daCosta KA, Youssef M, Hensey S. Conversion of dietary choline to trimethylamine and dimethylamine in rats: dose-response relationship. J Nutr. 1989; 119:800-4. [PubMed: 2723829]

[31]. Wang Z, Klipfell E, Bennett BJ, Koeth R, Levison BS, Dugar B, et al. Gut flora metabolism of phosphatidylcholine promotes cardiovascular disease. Nature. 2011; 472

[32]. Fuglestad AJ, Fink BA, Eckerle JK, Boys CJ, Hoecker HL, Kroupina MG, et al. Inadequate intake of nutrients essential for neurodevelopment in children with fetal alcohol spectrum disorders (FASD). Neurotoxicol Teratol. 2013

[33]. Albright CD, Tsai AY, Friedrich CB, Mar MH, Zeisel SH. Choline availability alters embryonic development of the hippocampus and septum in the rat. Brain Res Dev Brain Res. 1999; 113:1320.

[34]. Albright CD, Friedrich CB, Brown EC, Mar MH, Zeisel SH. Maternal dietary choline availability alters mitosis, apoptosis and the localization of TOAD-64 protein in the developing fetal rat septum. Brain Res Dev Brain Res. 1999; 115:123-9.

[35]. Ryan SH, Williams JK, Thomas JD. Choline supplementation attenuates learning deficits associated with neonatal alcohol exposure in the rat: effects of varying the timing of choline administration. Brain Res. 2008; 1237:91-100. [PubMed: 18786517]

[36]. Utsunomiya H, Takano K, Okazaki M, Mitsudome A. Development of the temporal lobe in infants and children: analysis by MR-based volumetry. AJNR Am J Neuroradiol. 1999; 20:71723. [PubMed: 10319988]

[37]. Li Q, Guo-Ross S, Lewis DV, Turner D, White AM, Wilson WA, et al. Dietary prenatal choline supplementation alters postnatal hippocampal structure and function. J Neurophysiol. 2004; 91:1545-55. [PubMed: 14645379]

[38]. Pyapali GK, Turner DA, Williams CL, Meck WH, Swartzwelder HS. Prenatal dietary choline supplementation decreases the threshold for induction of long-term potentiation in young adult rats. J Neurophysiol. 1998; 79:1790-6. [PubMed: 9535948]

[39]. Jones JP, Meck WH, Williams CL, Wilson WA, Swartzwelder HS. Choline availability to the developing rat fetus alters adult hippocampal long-term potentiation. Brain Res Dev Brain Res. 1999; 118:159-67.

[40]. Mellott TJ, Williams CL, Meck WH, Blusztajn JK. Prenatal choline supplementation advances hippocampal development and enhances MAPK and CREB activation. Faseb J. 2004; 18:545-7. [PubMed: 14715695]

[41]. Meck WH, Smith RA, Williams CL. Organizational changes in cholinergic activity and enhanced visuospatial memory as a function of choline administered prenatally or postnatally or both. Behav Neurosci. 1989; 103:1234-41. [PubMed: 2610916]

[42]. Williams CL, Meck WH, Heyer DD, Loy R. Hypertrophy of basal forebrain neurons and enhanced visuospatial memory in perinatally choline-supplemented rats. Brain Res. 1998; 794:225-38. [PubMed: 9622639]

[43]. Blusztajn JK, Wurtman RJ. Choline and cholinergic neurons. Science. 1983; 221:614-20. [PubMed: 6867732]

[44]. Holmes-McNary MQ, Loy R, Mar MH, Albright CD, Zeisel SH. Apoptosis is induced by choline deficiency in fetal brain and in PC12 cells. Brain Res Dev Brain Res. 1997; 101:9-16.

[45]. Yen CL, Mar MH, Meeker RB, Fernandes A, Zeisel SH. Choline deficiency induces apoptosis in primary cultures of fetal neurons. Faseb J. 2001; 15:1704-10. [PubMed: 11481217] 


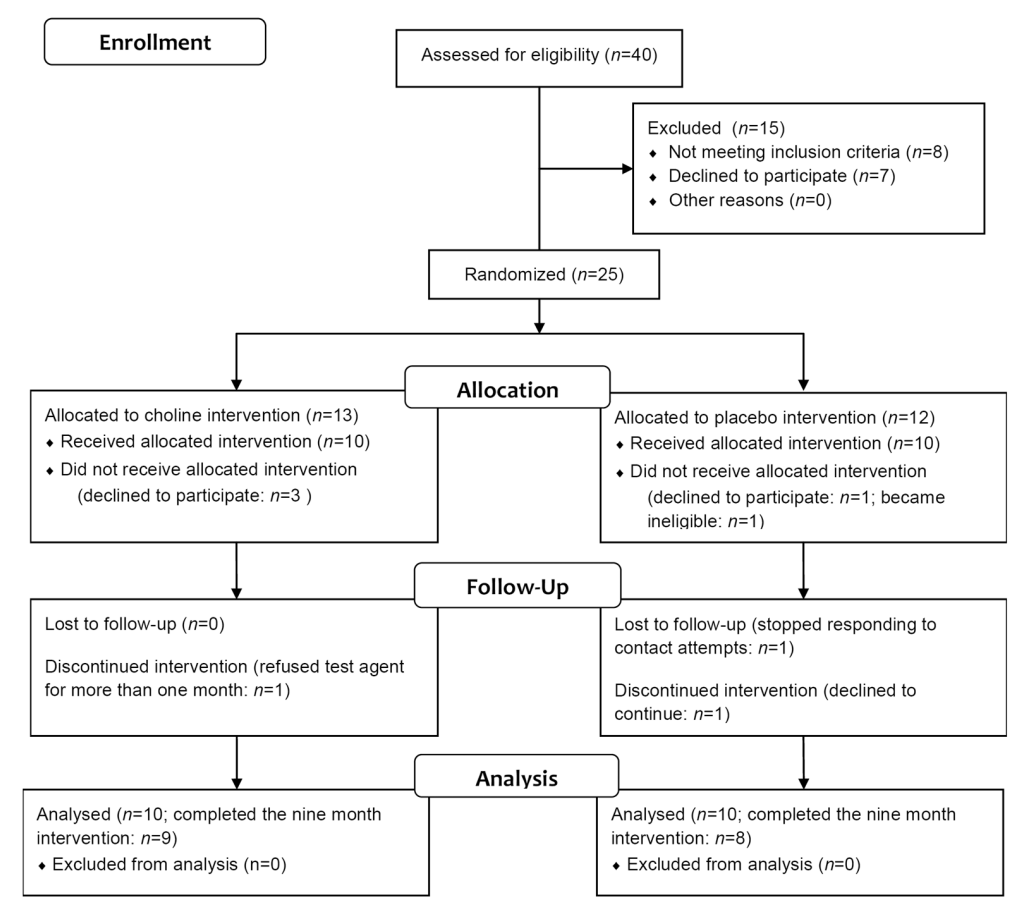

Figure 1.

Postnatal choline supplementation phase 1 study flow diagram 
Table 1

Baseline characteristics of participants receiving the allocated intervention.

\begin{tabular}{|c|c|c|c|}
\hline $\mathrm{N}(\%)$ or mean (SEM) & Choline ( $n=10)$ & Placebo $(n=10)$ & Statistical Test \\
\hline \multicolumn{4}{|l|}{ Age (years) } \\
\hline Mean & $3.9(0.3)$ & $4.3(0.1)$ & $t(18)=133, p=.20$ \\
\hline Range & $2.5-4.8$ & $3.8-4.8$ & \\
\hline \multicolumn{4}{|l|}{ Gender } \\
\hline Male & $3(30 \%)$ & $4(40 \%)$ & $p=1.00$ \\
\hline Female & $7(70 \%)$ & $6(60 \%)$ & - \\
\hline \multicolumn{4}{|l|}{ Racial Categories } \\
\hline White & $6(60 \%)$ & $5(50 \%)$ & $p=1.00$ \\
\hline Black or African American & $2(20 \%)$ & $2(20 \%)$ & - \\
\hline American Indian/Alaska Native & $1(10 \%)$ & $2(20 \%)$ & - \\
\hline More than one race & $1(10 \%)$ & $1(10 \%)$ & - \\
\hline \multicolumn{4}{|l|}{ Ethnic Category } \\
\hline Hispanic or Latino & $9(90 \%)$ & $9(90 \%)$ & $p=1.00$ \\
\hline Not Hispanic or Latino & $1(10 \%)$ & $1(10 \%)$ & - \\
\hline \multicolumn{4}{|l|}{ Dysmorphic Facial Features } \\
\hline Lip (score 4 or 5 ) & $4(40 \%)$ & $2(20 \%)$ & $p=0.63$ \\
\hline Philtrum (score 4 or 5) & $5(50 \%)$ & $1(10 \%)$ & $p=0.14$ \\
\hline Palpebral Fissure $\left(\leq 10^{\text {th }} \text { percentile }\right)^{a}$ & $3(33 \%)$ & $7(70 \%)$ & $p=0.18$ \\
\hline$\geq 2$ Facial Features Present & $3(30 \%)$ & $2(20 \%)$ & $p=1.00$ \\
\hline \multicolumn{4}{|l|}{ Growth Deficiency ( $\leq 10^{\text {th }}$ percentile) } \\
\hline Height & $2(20 \%)$ & $0(0 \%)$ & $p=0.47$ \\
\hline Weight & $3(30 \%)$ & $1(10 \%)$ & $p=0.58$ \\
\hline \multicolumn{4}{|l|}{ Deficient Brain Growth $\left(\leq 10^{\text {th }}\right.$ percentile) } \\
\hline Occipital-Frontal Circumference & $2(20 \%)$ & $0(0 \%)$ & $p=0.47$ \\
\hline \multicolumn{4}{|l|}{ Alcohol / Drug Exposure } \\
\hline Alcohol Confirmed & $7(70 \%)$ & $10(100 \%)$ & $p=0.21$ \\
\hline Alcohol Suspected & $3(30 \%)$ & $0(0 \%)$ & - \\
\hline Other Drug Exposure Suspected & $6(60 \%)$ & $8(80 \%)$ & $p=0.63$ \\
\hline \multicolumn{4}{|l|}{ IOM Diagnostic Category } \\
\hline FAS & $2(20 \%)$ & $4(40 \%)$ & $p=0.39$ \\
\hline Partial FAS & $4(40 \%)$ & $1(10 \%)$ & - \\
\hline ARND & $4(40 \%)$ & $5(50 \%)$ & - \\
\hline \multicolumn{4}{|l|}{ Baseline Cognitive Functioning } \\
\hline Mullen Visual Reception & $47.2(3.3)$ & $53.2(5.6)$ & $t(18)=0.92, p=0.37$ \\
\hline Mullen Fine Motor & $42.9(2.7)$ & $46.1(5.0)$ & $t(18)=0.56, p=0.58$ \\
\hline Mullen Expressive Language & $43.0(2.7)$ & $39.6(3.3)$ & $t(18)=-0.80, p=0.44$ \\
\hline Mullen Receptive Language & $46.3(2.6)$ & $42.9(3.2)$ & $t(18)=-0.82, p=0.42$ \\
\hline Mullen Total Score & $90.2(4.4)$ & $92.2(7.1)$ & $t(18)=0.24, p=0.81$ \\
\hline Taking Any Psychotropic Medication & $1(10 \%)$ & $2(20 \%)$ & $X^{2}(1)=0.39, p=.53$ \\
\hline
\end{tabular}

Nutr Res. Author manuscript; available in PMC 2014 November 01. 
Comparisons between treatment groups were conducted using independent samples $t$-tests for normally-distributed continuous variables. Betweengroup comparisons for frequencies of categorical variables were conducted using Fisher's Exact Test. Only $p$ values are reported with Fisher's Exact Test.

${ }^{a}$ Palpebral fissure length was missing for one participants who was uncooperative and from whom an accurate measure could not be obtained (choline: $n=9$ ). 
Table 2

Study compliance based on calendar logsheets, packet counts, and 24-hour dietary recalls.

\begin{tabular}{|c|c|c|c|}
\hline $\mathrm{N}(\%)$, median (IQR), or mean (SEM) & Choline $(n=10)$ & Placebo $(n=9)$ & Statistical Test \\
\hline \multicolumn{4}{|c|}{ Logsheets: Days the Allocated Intervention was Received ${ }^{a}(\%$ Days in the Study) } \\
\hline Any Dose & $87 \%(69-92)$ & $84 \%(65-97)$ & $p=.66$ \\
\hline Full Dose & $75 \%(47-84)$ & $84 \%(57-96)$ & $p=.32$ \\
\hline Partial Dose & $10 \%(1-13)$ & $7 \%(0-12)$ & $p=.55$ \\
\hline \multicolumn{4}{|c|}{ Logsheets: Reason No Allocated Intervention was Received ${ }^{a}$ (\% Days in the Study) } \\
\hline Child Refused & $3 \%(1-11)$ & $0 \%(0-16)$ & $p=.66$ \\
\hline Child Sick & $0 \%(0-4)$ & $0 \%(0-2)$ & $p=.97$ \\
\hline Parent Forgot & $3 \%(1-11)$ & $2 \%(0-10)$ & $p=.50$ \\
\hline Other & $1 \%(0-5)$ & $3 \%(1-5)$ & $p=.55$ \\
\hline Empty packets (\% returned $)^{a}$ & $83 \%(56-87)$ & $73 \%(39-89)$ & $p=.84$ \\
\hline \multicolumn{4}{|c|}{ Daily Choline Intake From Diet (mg/day): All Participants ${ }^{b}$} \\
\hline Baseline & $155(17)$ & $187(24)$ & $t(18)=1.10, p=.87$ \\
\hline 3 month & $204(22)$ & $212(42)$ & $t(18)=0.16, p=.29$ \\
\hline 6 month & $191(20)$ & $153(16)$ & $t(16)=-1.50, p=.15$ \\
\hline 9 month & $187(38)$ & $217(25)$ & $t(15)=0.64, p=.53$ \\
\hline \multicolumn{4}{|c|}{ Daily Choline Intake From Diet (mg/day): Ages $1-3$ years } \\
\hline Baseline ( $n=7)$ & $137(32)$ & $211(59)$ & $t(5)=1.19, p=.29$ \\
\hline 3 month $(n=4)$ & $133(5)$ & 115 & \\
\hline 6 month $(n=2)$ & $149(17)$ & $-c$ & \\
\hline 9 month $(n=2)$ & $142(31)$ & $-c$ & \\
\hline \multicolumn{4}{|c|}{ Daily Choline Intake From Diet (mg/day): Ages $4-8$ years } \\
\hline Baseline $(n=13)$ & $172(37)$ & $181(17)$ & $t(11)=0.24, p=.82$ \\
\hline 3 month $(n=13)$ & $243(24)$ & $224(45)$ & $t(11)=-0.30, p=.77$ \\
\hline 6 month $(n=16)$ & $203(23)$ & $153(16)$ & $t(14)=-1.84, p=.09$ \\
\hline 9 month ( $n=2)$ & $200(48)$ & $196(58)$ & $t(13)=-0.07 p=.94$ \\
\hline \multicolumn{4}{|l|}{ Taking a Daily Nutritional Supplement } \\
\hline Baseline & $2(20 \%)$ & $6(60 \%)$ & $X^{2}(1)=3.33, p=.07$ \\
\hline Started After Baseline & $2(20 \%)$ & $1(10 \%)$ & $\mathrm{X}^{2}(1)=0.39, p=.53$ \\
\hline
\end{tabular}

Comparisons between treatment groups were conducted using independent samples $t$-tests for means of normally-distributed continuous variables and using Mann-Whitney $\mathrm{U}$ tests for medians of non-normally-distributed variables. Between-group comparisons for frequencies of categorical variables were conducted using Fisher's Exact Test. Only $p$ values are reported with Mann-Whitney U tests and Fisher's Exact Test.

a Medians and interquartile range (IQR) are reported.

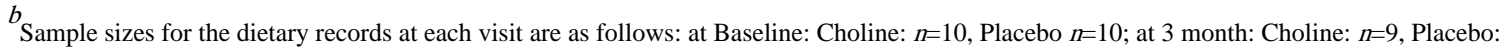
$n=9$; at 6 month: Choline: $n=9$, Placebo: $n=9$; at 9 month: Choline: $n=9$, Placebo: $n=8$.

${ }^{c}$ No participants in this age range were in the placebo group. 
Table 3

Physical symptoms at baseline and adverse events (new symptoms) during the course of the study.

\begin{tabular}{|c|c|c|c|}
\hline $\mathbf{N}(\%)$ & Choline $(n=9)^{a}$ & Placebo $(n=10)$ & Statistical Test \\
\hline \multicolumn{4}{|c|}{ Administration Problems with the Supplement } \\
\hline Baseline & - & - & - \\
\hline During Study & $7(78 \%)$ & $6(60 \%)$ & $p=0.63$ \\
\hline \multicolumn{4}{|l|}{ General Health } \\
\hline Baseline & $3(33 \%)$ & $0(0 \%)$ & $p=0.09$ \\
\hline During Study & $7(78 \%)$ & $3(30 \%)$ & $p=0.07$ \\
\hline \multicolumn{4}{|l|}{ Skin } \\
\hline Baseline & $3(33 \%)$ & $5(50 \%)$ & $p=0.65$ \\
\hline During Study & $3(33 \%)$ & $3(30 \%)$ & $p=1.00$ \\
\hline \multicolumn{4}{|l|}{ Ear, Nose, Throat } \\
\hline Baseline & $4(44 \%)$ & $4(40 \%)$ & $p=1.00$ \\
\hline During Study & $2(22 \%)$ & $6(60 \%)$ & $p=0.17$ \\
\hline \multicolumn{4}{|l|}{ Cardiovascular } \\
\hline Baseline & $1(11 \%)$ & $1(10 \%)$ & $p=1.00$ \\
\hline During Study & $1(11 \%)$ & $0(0 \%)$ & $p=0.47$ \\
\hline \multicolumn{4}{|l|}{ Respiratory } \\
\hline Baseline & $4(44 \%)$ & $2(20 \%)$ & $p=0.35$ \\
\hline During Study & $5(56 \%)$ & $2(20 \%)$ & $p=0.17$ \\
\hline \multicolumn{4}{|l|}{ Gastrointestinal } \\
\hline Baseline & $5(56 \%)$ & $5(50 \%)$ & $p=1.00$ \\
\hline During Study & $7(78 \%)$ & $5(50 \%)$ & $p=0.35$ \\
\hline \multicolumn{4}{|l|}{ Genitourinary } \\
\hline Baseline & $1(11 \%)$ & $1(10 \%)$ & $p=1.00$ \\
\hline During Study & $1(11 \%)$ & $5(50 \%)$ & $p=0.14$ \\
\hline \multicolumn{4}{|l|}{ Musculoskeletal } \\
\hline Baseline & $0(0 \%)$ & $1(10 \%)$ & $p=1.00$ \\
\hline During Study & $1(11 \%)$ & $2(20 \%)$ & $p=1.00$ \\
\hline \multicolumn{4}{|l|}{ Neurological } \\
\hline Baseline & $7(78 \%)$ & $7(70 \%)$ & $p=1.00$ \\
\hline During Study & $6(67 \%)$ & $7(70 \%)$ & $p=1.00$ \\
\hline \multicolumn{4}{|l|}{ Allergy } \\
\hline Baseline & $0(0 \%)$ & $3(30 \%)$ & $p=0.21$ \\
\hline During Study & $1(11 \%)$ & $1(10 \%)$ & $p=1.00$ \\
\hline \multicolumn{4}{|l|}{ Other } \\
\hline Baseline & $0(0 \%)$ & $1(10 \%)$ & $p=1.00$ \\
\hline During Study & $3(33 \%)$ & $2(20 \%)$ & $p=0.63$ \\
\hline
\end{tabular}

Between-group comparisons for frequencies of categorical variables were conducted using Fisher's Exact Test. Only $p$ values are reported with Fisher's Exact Test. 
${ }^{a}$ Only those participants who received the allocated intervention were included in analyses. One participant in the choline group refused the allocated intervention (i.e., consumed only one dose) and was excluded from the analyses. 
Table 4

Serum choline and metabolite levels at baseline and follow-up visits.

\begin{tabular}{|c|c|c|c|}
\hline mean (SEM) & Choline $(n=9)^{a}$ & $\operatorname{Placebo}(n=10)^{a}$ & Statistical Test \\
\hline \multicolumn{4}{|c|}{ Choline $(\mu \mathrm{mol} / \mathrm{L})$} \\
\hline Baseline & $7.33(0.60)$ & $7.17(0.54)$ & $t(16)=-0.20, p=.84$ \\
\hline 1 month & $15.07(1.60)$ & $8.18(1.23)$ & $t(15)=-3.45, p=.004^{*}$ \\
\hline 6 month & $15.03(1.42)$ & $6.88(0.70)$ & $t(11)=-4.88, p<.001^{*}$ \\
\hline 9 month & 14.77 (1.09) & $7.07(0.77)$ & $t(11)=-5.57, p<.001^{*}$ \\
\hline \multicolumn{4}{|c|}{ Betaine $(\mu \mathrm{mol} / \mathrm{L})$} \\
\hline Baseline & $54.52(5.32)$ & $52.88(3.14)$ & $t(16)=-0.28, p=.78$ \\
\hline 1 month & $121.07(17.95)$ & $68.91(13.95)$ & $t(15)=-2.32, p=.04 *$ \\
\hline 6 month & $111.90(19.05)$ & $58.22(8.75)$ & $t(11)=-2.42, p=.03^{*}$ \\
\hline 9 month & $122.23(27.17)$ & $49.58(6.89)$ & $t(11)=-2.41, p=.04 *$ \\
\hline \multicolumn{4}{|c|}{ Phosphatidylcholine $(\mu \mathrm{mol} / \mathrm{L})$} \\
\hline Baseline & $1645(67)$ & $1734(82)$ & $t(16)=-0.81, p=.43$ \\
\hline 1 month & $1771(92)$ & $1758(128)$ & $t(15)=-0.08, p=.94$ \\
\hline 6 month & $1833(154)$ & $1728(111)$ & $t(11)=-0.54, p=.60$ \\
\hline 9 month & $1689(145)$ & $1759(88)$ & $t(11)=0.39, p=.70$ \\
\hline \multicolumn{4}{|c|}{ Sphingomyelin $(\mu \mathrm{mol} / \mathrm{L})$} \\
\hline Baseline & $547(53)$ & $430(20)$ & $t(16)=-2.24, p=.04^{*}$ \\
\hline 1 month & $538(35)$ & $456(17)$ & $t(15)=-2.17, p=.05^{*}$ \\
\hline 6 month & $404(34)$ & $491(67)$ & $t(11)=-1.21, p=.25$ \\
\hline 9 month & 361 (19) & $364(21)$ & $t(11)=0.11, p=.91$ \\
\hline
\end{tabular}

Comparisons between treatment groups were conducted using independent samples $t$-tests for normally-distributed continuous variables.

${ }^{a}$ Sample sizes at each visit are as follows: at Baseline: Choline: $n=8$, Placebo: $n=10$; at 1 month: Choline: $n=8$, Placebo: $n=9$; at 6 month: Choline: $n=7$, Placebo: $n=6$; at 9 month: Choline: $n=7$, Placebo: $n=6$ 